\title{
Hepatocyte Transplantation Attenuates the Course of Acute Liver Failure Induced by Thioacetamide in Lewis Rats
}

\author{
E. KOBLIHOVÁ ${ }^{1^{*}}$, O. LUKŠAN ${ }^{2 *}$, I. MRÁZOVÁ ${ }^{2}$, M. RYSKA ${ }^{1}$, L. ČERVENKA ${ }^{2,3}$ \\ "These authors contributed to the present study equally.
}

${ }^{1}$ Department of Surgery, Second Faculty of Medicine, Charles University and Central Military Hospital, Prague, Czech Republic, ${ }^{2}$ Center for Experimental Medicine, Institute for Clinical and Experimental Medicine, Prague, Czech Republic, ${ }^{3}$ Department of Pathophysiology, Second Faculty of Medicine, Charles University, Prague, Czech Republic

Received September 22, 2014

Accepted December 12, 2014

On-line March 24, 2015

\section{Summary}

Acute liver failure (ALF) is a clinical syndrome resulting from widespread damage of hepatocytes, with extremely high mortality rate. Urgent orthotopic liver transplantation was shown to be the most effective therapy for ALF but this treatment option is limited by scarcity of donor organs. Therefore, hepatocyte transplantation ( $\mathrm{Tx}$ ) has emerged as a new therapeutical measure for ALF, however, the first clinical applications proved unsatisfactory. Apparently, extensive preclinical studies are needed. Our aim was to examine if hepatocytes isolated from transgenic "firefly luciferase" Lewis rats into the recipient liver would attenuate the course of thioacetamide (TAA)-induced ALF in Lewis rats. Untreated Lewis rats after TAA administration showed a profound decrease in survival rate; no animal survived $54 \mathrm{~h}$. The rats showed marked increases in plasma alanine aminotransferase (ALT) and aspartate aminotransferase (AST) activities, in plasma level of bilirubin and ammonia $\left(\mathrm{NH}_{3}\right)$, and in a significant decrease in plasma albumin. Hepatocyte $T x$ attenuated the course of TAA-induced ALF Lewis rats which was reflected by improved survival rate and reduced degree of liver injury showing as lowering of elevated plasma ALT, AST, $\mathrm{NH}_{3}$ and bilirubin levels and increasing plasma albumin. In addition, bioluminescence imaging analyses have shown that in the TAA-damaged livers the transplanted hepatocyte were fully viable throughout the experiment. In conclusion, the results show that hepatocyte $T x$ into the liver can attenuate the course of TAA-induced ALF in Lewis rats. This information should be considered in attempts to develop new therapeutic approaches to the treatment of ALF.

\section{Key words}

Acute liver failure • Thioacetamide • Hepatocyte transplantation

\section{Corresponding author}

L. Červenka, Department of Pathophysiology, Second Faculty of Medicine, Charles University, Prague, Czech Republic. E-mail: luce@medicon.cz

\section{Introduction}

The liver is one of the most versatile and biologically active organs whose key functions include: a) filtration and storage of blood; b) crucial participation in body metabolism of carbohydrates, lipids, proteins and hormones, as well as the synthesis of albumin and coagulation factors; c) detoxification and biotransformation of foreign chemicals; and d) excretion of protein-bound/lipid-soluble waste products (Suchy 2009).

Therefore liver failure or insufficiency is a lifethreatening condition. Acute liver failure (ALF) is a clinical syndrome resulting from widespread damage of hepatocytes with resultant loss of liver function. ALF is a rare orphan disorder which according to the statistics of the Acute Liver Failure Study Group (ALFSG, a consortium of investigators and academic clinical centers and the most reliable source of ALF data www.acuteliver.org) affects yearly 2000 people in the U.S. (Bernal and Wendon 2013, Lee 2012, Lee et al. 2012, Saliba and Saumel 2013, Zhao et al. 2013). The

PHYSIOLOGICAL RESEARCH • ISSN 0862-8408 (print) • ISSN 1802-9973 (online)

(C) 2015 Institute of Physiology v.v.i., Academy of Sciences of the Czech Republic, Prague, Czech Republic

Fax+420 241062 164, e-mail: physres@biomed.cas.cz, www.biomed.cas.cz/physiolres 
cardinal signs displayed by ALF patients are coagulopathy and hepatic encephalopathy, which are the consequence of the loss of hepatocyte capability of synthesizing clotting factors and of removing ammonia $\left(\mathrm{NH}_{3}\right)$, respectively. Treatment of ALF remains supportive and continues to be one of the most challenging problems in clinical medicine (Bernal and Wendon 2013, Lee 2012, Lee et al. 2012, Saliba and Saumel 2013), and despite the progress in this field and unique liver regeneration ability only $45 \%$ of patients with ALF will spontaneously recover (Bernal and Wendon 2013, Lee 2012, Lee et al. 2012, Saliba and Saumel 2013). For the remaining $55 \%$ emergency orthotopic liver transplantation (OLT) is currently the only effective therapeutical approach. However, this treatment option has limited application, primarily due to the scarcity of donor organs in general and especially those available on short notice. The other problems are the invasiveness of OLT procedure in seriously ill patients and also the high cost of this procedure (Berg et al. 2011, Bernal and Wendon 2013, Germani et al. 2012, Yamashiki et al. 2012). Moreover, currently existing prognostic criteria are inadequate to predict who will recover from ALF without the need for OLT and who will die (Berg et al. 2011, Bernal and Wendon 2013, Mao et al. 2014, Wlodzimirow et al. 2012, Zhao et al. 2013). Therefore, in order to develop bridging techniques enabling survival until an organ becomes available for OLT or until liver function recovers, other treatment approaches, such as artificial and bioartificial liver support have been investigated for more than three decades (Banares et al. 2013, Booth et al. 2012, Fukumitsu et al. 2011, Pless 2010, Sgroi et al. 2009, Struecker et al. 2014). However, the effectiveness of these new methods is inadequate: it is now clear that artificial devices that would satisfactorily replace diverse liver functions and support a sophisticated process of the regeneration of a deteriorating organ are still not available (Banares et al. 2013, Booth et al. 2012, Fukumitsu et al. 2011, Pless 2010, Sgroi et al. 2009, Struecker et al. 2014). Moreover, it is important to emphasize that for ALF, a rare orphan disease affecting only a small number of patients, large controlled clinical trials are not available and therefore evidence-based medicine in this field is almost absent (Banares et al. 2013, Struecker et al. 2014).

All these facts considered, hepatocyte transplantation (Tx) has emerged as a new therapeutical approach to ALF (Dhawn et al. 2010, Hughes et al. 2012,
Pareja et al. 2014, Sgroi et al. 2009), however, first therapeutic attempts proved unsatisfactory (Dhawn et al. 2010, Hughes et al. 2012, Pareja et al. 2014, Tritto et al. 2012, Yu et al. 2012). Therefore the need for extensive preclinical testing became obvious (Amano et al. 2011, Eguchi et al. 1997, Wertheim et al. 2012). One crucial challenge is to unequivocally identify and track the viability of the transplanted hepatocytes in the host throughout the study. A recent development of transgenic rats expressing ubiquitously the gene for luciferase derived from the firefly (Photinus pyralis) is a major technological achievement in this field because it allows bioluminescence imaging (BLI) of the transplanted cells in vivo (Hakamata et al. 2006). Using this technique, the same recipient can be repeatedly examined throughout the study without the need for animals to be killed at each time point (Hakamata et al. 2006, Kasahara et al. 2013, Maeda et al. 2013). Moreover, it was shown that an immunological reaction or immunosuppressive therapy substantially altered the function of the transplanted cells (Kawahara et al. 2010, Loukopoulos et al. 2014, Wu et al. 2010). Since the transgenic "firefly luciferase rat" was developed on the background of an inbred rat strain (Lewis rats), the studies of transplanted hepatocytes can be performed without a need for post-Tx immunosuppression (Hakamata et al. 2006, Kasahara et al. 2013, Maeda et al. 2013). It is also noteworthy that in our recent study (Koblihová et al. 2014) we developed and characterized a highly reproducible model of thioacetamide (TAA)-induced ALF in Lewis rats which, in our opinion, is optimal for evaluation of new approaches to the therapy of ALF.

Based on the above considerations, we decided to examine if hepatocyte Tx into the liver via portocaval application would attenuate the course of TAA-induced ALF in Lewis rats. Furthermore, to gain more insight in the viability of transplanted hepatocytes, longitudinal in vivo BLI analysis of the transplanted cells in healthy and TAA-induced ALF Lewis rats was performed.

\section{Methods}

Ethical approval, animals, chemicals, and isolation and transplantation (Tx) of hepatocytes

The studies were performed in accordance with guidelines and practices established by the Animal Care and Use Committee of the Institute for Clinical and Experimental Medicine, Prague, which accord with the European Convention on Animal Protection and 
Guidelines on Research Animal Use. All the animals used in the study were housed in facilities accredited by the Czech Association of Laboratory Animal Care. The experiments were performed in male Lewis rats that were purchased from Charles River Laboratories (Velaz, Prague, Czech Republic) at the age of 9 weeks. Before starting experiments the rats were acclimatized in our vivarium during two weeks. The animals were kept on a 12-h/12-h light/dark cycle. The luciferase Lewis transgenic rats (luc-Lew-Tg) were supplied as stock animals from the Division of Organ Replacement Research, Center for Molecular Medicine, Jichi Medical School, Tochigi, Japan. The generation and characterization of luc-Lew $\mathrm{Tg}$ inbred strain model is described in the original study by Hakamata and co-workers (Hakamata et al. 2006). Throughout the experiments rats were fed a normal salt, normal protein diet $(0.45 \% \mathrm{NaCl}, 19-21 \%$ protein, SEMED, Prague, Czech Republic) and had free access to tap water. TAA (Sigma, Prague, Czech Republic) was dissolved in physiological saline and the appropriate dose was injected i.p. In the present study freshly prepared TAA was administrated i.p. in two injections, on day 0 at 8:00 AM and 20:00 PM in the total amount $525 \mathrm{mg} \cdot \mathrm{kg}^{-1}$ of BW. This dose was chosen based on our recent study evaluating the optimal doses of TAA for induction of ALF; we showed that after this dose all Lewis rats developed ALF and without treatment succumbed within first 48 h (Koblihová et al. 2014). Control rats received i.p. injections of physiological saline. Under general anesthesia (thiopental sodium $50 \mathrm{mg} \cdot \mathrm{kg}^{-1}$ of $\mathrm{BW}$ ) male luc-Lwe-Tg weighing 250-280 g underwent abdominal " $U$ " incision for hepatocytes isolation which was performed by the two-step collagenase perfusion method (Berry et al. 1991, Garnol et al. 2014, Seglen 1976). The viability of isolated hepatocytes was assessed by the trypan blue exclusion test (Berry et al. 1991, Garnol et al. 2014, Seglen 1976) and in our experiments ranged between 93 to $95 \%$. Isolated hepatocytes from luc-Lwe$\mathrm{Tg}$ in the amount $2 \times 10^{6}$ cells dissolved in the $600 \mu \mathrm{l}$ physiological saline solution were implanted into the liver through the portal vein. In this regard, it is important to highlight that the amount of transplanted hepatocytes employed in in the present study was derived from previous studies that successfully used hepatocytes transplantation as a tool for the treatment of liver-based metabolic defects (for review see Filippi and Dhawan 2014). Thus, the optimal cell number to be transplanted was calculated at $5 \times 10^{6} \cdot \mathrm{kg}^{-1} \mathrm{BW}$, which represent about
$5 \%$ of parenchymal cell mass from the liver and it has been reported that this quantity of transplanted hepatocytes is sufficient to restore metabolic liver function in liver-based metabolic diseases (for review see Filippi and Dhawan 2014). Based on this notion and in accordance with the BW of animals, the aforementioned amount of hepatocytes (i.e. $2 \times 10^{6}$ ) was transplanted. In accordance with these findings in liver-based metabolic diseases, also other investigators have recently started to use similar amount of cells for the treatment of ALF (Amano et al. 2011, Fukumitsu et al. 2011, Jitraruch et al. 2014, Loukopoulos et al. 2014, Puppi et al. 2014). Untreated rats (without hepatocyte Tx) received $600 \mu 1$ of physiological solution by the same route.

\section{Experimental design}

Series 1: Effects of hepatocytes transplantation on the course of TAA-induced ALF in Lewis rats

Twenty-four hours before i.p. administration ("-24 h") blood sample (about 200 to $300 \mu \mathrm{l}$ ) was taken from the tail vein, for biochemical analyses (Fuji DriveChem 4000 Analyser). Plasma levels of albumin, bilirubin, alanine aminotransferase (ALT) and aspartate aminotransferase (AST) activities, and ammonia level $\left(\mathrm{NH}_{3}\right)$ were determined. Blood samples for the same analyses were also taken 24, 48, 72, 96 and $168 \mathrm{~h}$ after first administration of TAA. The follow-up period in this series was $168 \mathrm{~h}$ and at the end of experiments surviving animals were killed by an overdose of pentobarbital. Since during ALF development the animals' food and water intake are dramatically reduced, 5\% glucose solution, $2 \mathrm{ml} / 100 \mathrm{~g} \mathrm{BW}$, was administered subcutaneously every morning to prevent dehydration; our recent study demonstrated that this procedure is an effective remedy (Koblihová et al. 2014). Hepatocyte Tx was performed $24 \mathrm{~h}$ after first TAA administration. The survival rate was monitored every $8 \mathrm{~h}$, BW was monitored every $24 \mathrm{~h}$ and blood samples were taken as described above.

The following experimental groups were investigated (initial $n=20$ in each group):

1. Lewis rats + physiological saline + hepatocyte $\mathrm{Tx}$ (Lewis rats + hepatocytes Tx)

2. Lewis rats $+\mathrm{TAA}+$ physiological saline (Untreated Lewis rats with ALF)

3. Lewis rats + TAA + hepatocyte Tx (Lewis rats with $\mathrm{ALF}+$ hepatocytes Tx) 
Series 2: Hepatocyte viability assessed by BLI analysis after $T x$ in Lewis rats

The reliability of BLI analyses of transplanted cells isolated from luc-Lew-Tg was described and validated in previous studies (Hakamata et al. 2006, Kasahara et al. 2013, Maeda et al. 2013). Therefore in our experiments the same technique was used. In this series, in vivo luciferase imaging of hepatocytes after Tx was obtained by using noninvasive IVIS XR system (Caliper, Hopkinton, MA, USA). Rats were anesthetized with $2 \%$ isoflurane and D-luciferin $(30 \mathrm{mg} / \mathrm{ml}$ solution in physiological saline, Caliper, Hopkinton, MA, USA) was administrated at a dose of $50 \mathrm{mg} \cdot \mathrm{kg}^{-1}$ of $\mathrm{BW}$ via the femoral vein. The signal intensity was quantified as photon flux in units of photons. $\mathrm{sec}^{-1} \cdot \mathrm{cm}^{-2}$ in the region of interest by using Living Image software. BLI analyses were performed 24, 48, 72, 96 and $168 \mathrm{~h}$ after hepatocyte Tx. The following experimental groups were examined ( $n=8$ in each group):

1. Lewis rats + hepatocyte $T x$

2. Lewis rats with ALF + hepatocyte Tx

It is important to underscore that in this series a separate groups of animals were used as compared with series \#1 (in another words BLI analyses was performed on different animals than in series \#1).
A

Lewis rats + hepatocytes Tx

Lewis rats with ALF + hepatocytes Tx

: Untreated Lewis rats with ALF

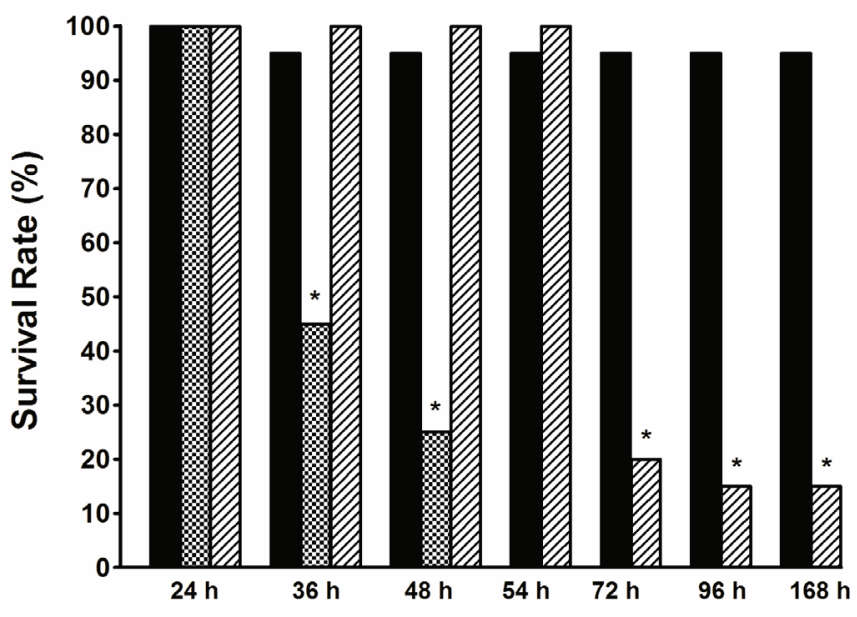

B $\square$ Lewis rats with ALF + hepatocytes Tx

Ontreated Lewis rats with ALF
Fig. 1. The survival rate (A) and plasma ammonia $\left(\mathrm{NH}_{3}\right)$ levels $(\mathbf{B})$ in healthy Lewis rats exposed to hepatocyte transplantation (Lewis rats + hepatocyte Tx), in Lewis rats with acute liver failure without treatment (untreated Lewis rats with ALF) and in Lewis rats with acute liver failure treated with hepatocyte transplantation (Lewis rats with ALF + hepatocyte Tx). * $\mathrm{P}<0.05$ versus the value for Lewis rats + hepatocyte Tx at the same time point. ${ }^{\#} \mathrm{P}<0.05$ versus all the other values at the same time point.

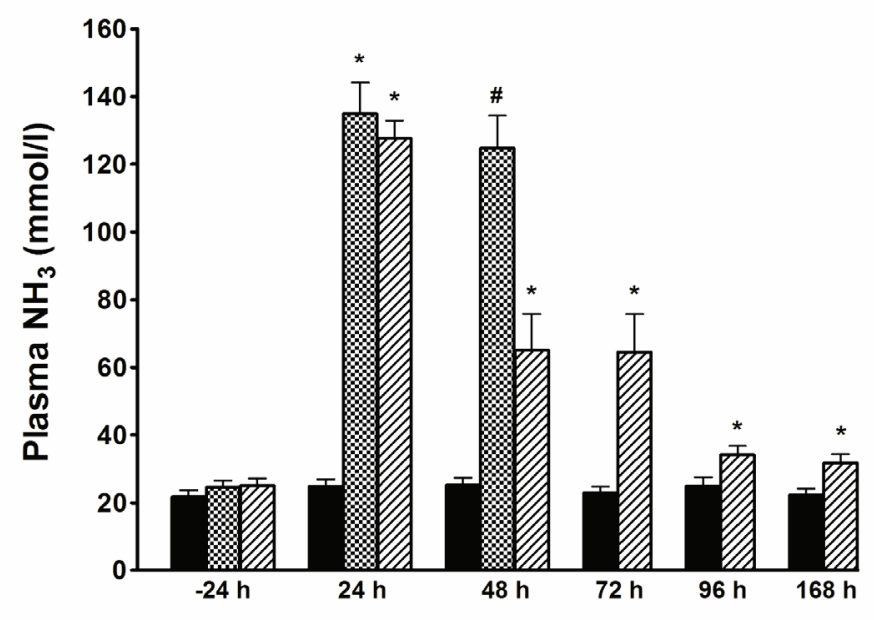




\section{Statistical analysis}

Statistical analysis of the data was performed using Graph-Pad Prism software (Graph Pad Software, San Diego, CA, USA). ANOVA for repeated measurements, followed by Student-Newman-Keuls test, was performed for analysis of changes within the groups. Statistical comparison of other results was made by Student's t-test or one-way ANOVA. Unless indicated otherwise, values are expressed as mean \pm S.E.M. A p-value less than 0.05 was considered statistically significant.

\section{Results}

Series 1: Effects of hepatocyte transplantation on the course of TAA-induced ALF in Lewis rats

As shown in Figure 1A, TAA administration in untreated Lewis rats dramatically decreased survival rate (48 $\mathrm{h}$ after TAA administration only $25 \%$ of animals were alive) and no animal survived $54 \mathrm{~h}$. Hepatocyte Tx markedly improved the survival rate after TAA (all animals remained alive at $54 \mathrm{~h}$ after TAA administration) with the final survival rate of $15 \%$. One of healthy Lewis rats died within $36 \mathrm{~h}$ after Tx.

\section{A}

Lewis rats + hepatocytes $\mathrm{Tx}$

Ontreated Lewis rats with ALF

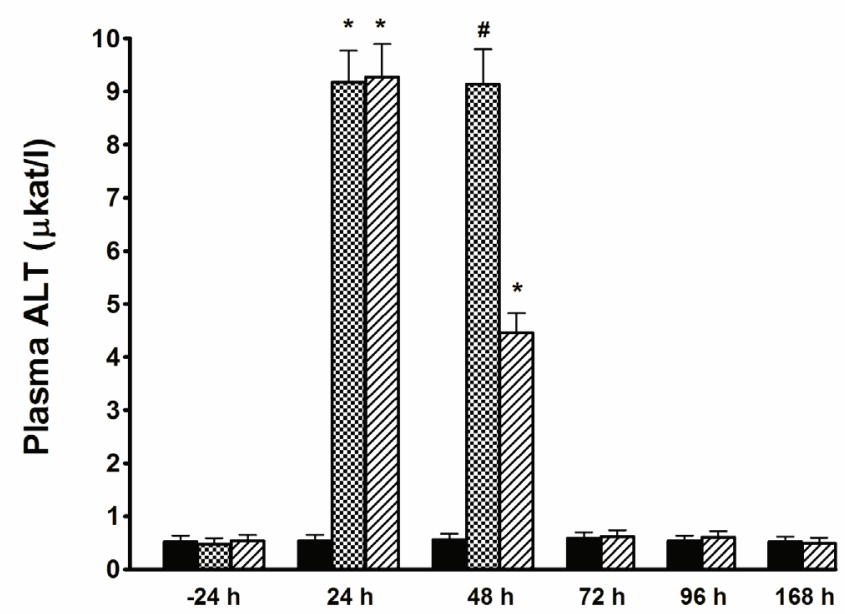

$\oslash$ Lewis rats with ALF + hepatocytes Tx
Lewis rats + hepatocytes Tx

Lewis rats with ALF + hepatocytes Tx
Fig. 2. Changes in plasma alanine aminotransferase (ALT) (A) and aspartate aminotransferase (AST) (B) activities in healthy Lewis rats exposed to hepatocytes transplantation (Lewis rats + hepatocyte $\mathrm{Tx}$ ), in Lewis rats with acute liver failure without treatment (untreated Lewis rats with ALF) and in Lewis rats with acute liver failure treated with hepatocyte transplantation (Lewis rats with ALF + hepatocyte $\mathrm{Tx}$ ). * $\mathrm{P}<0.05$ versus the value for Lewis rats + hepatocytes $T x$ at the same time point. ${ }^{\#} \mathrm{P}<0.05$ versus all the other values at the same time point.

Ontreated Lewis rats with ALF

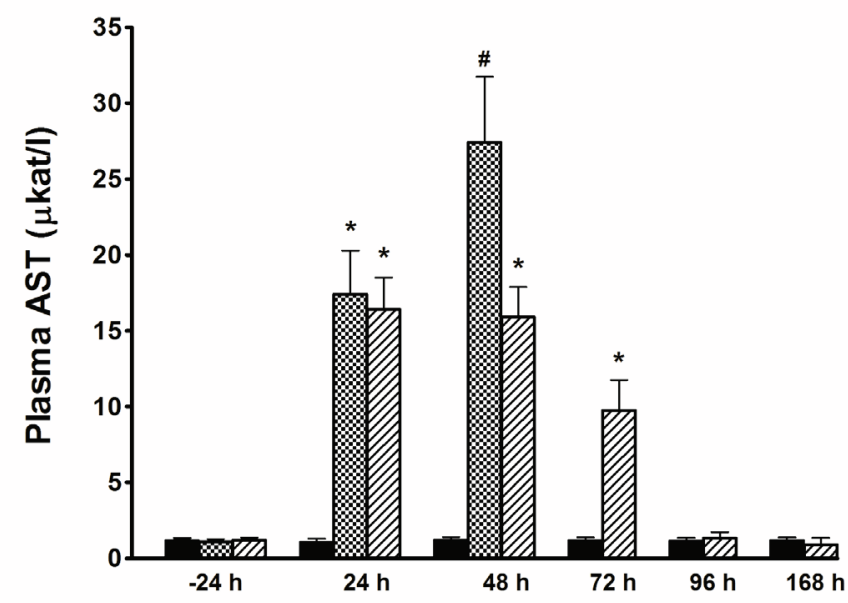


A

Lewis rats + hepatocytes Tx $\square$ Lewis rats with ALF + hepatocytes Tx

Ontreated Lewis rats with ALF

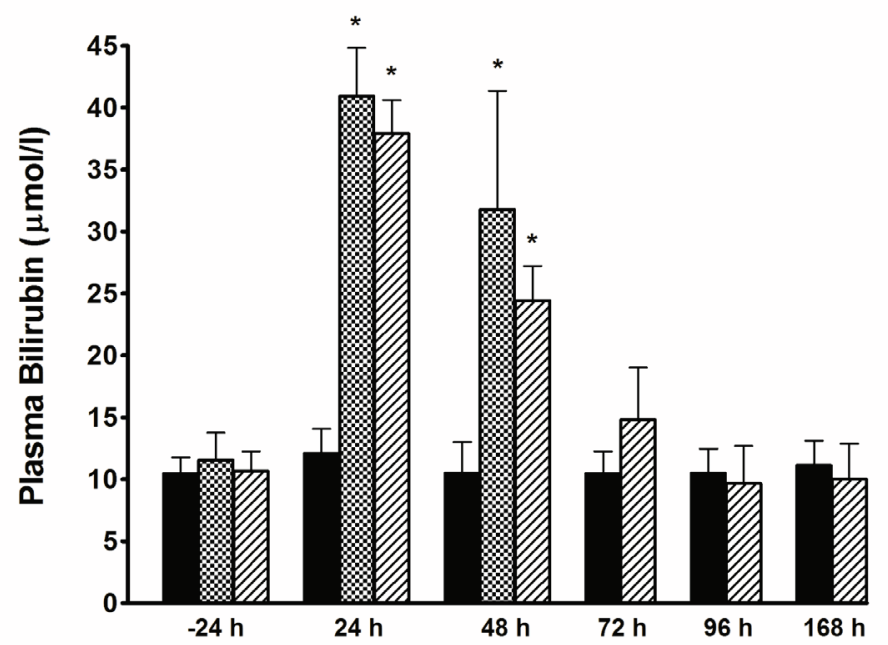

B

Lewis rats + hepatocytes $\mathrm{Tx} \quad \square$ Lewis rats with ALF + hepatocytes Tx

O Untreated Lewis rats with ALF

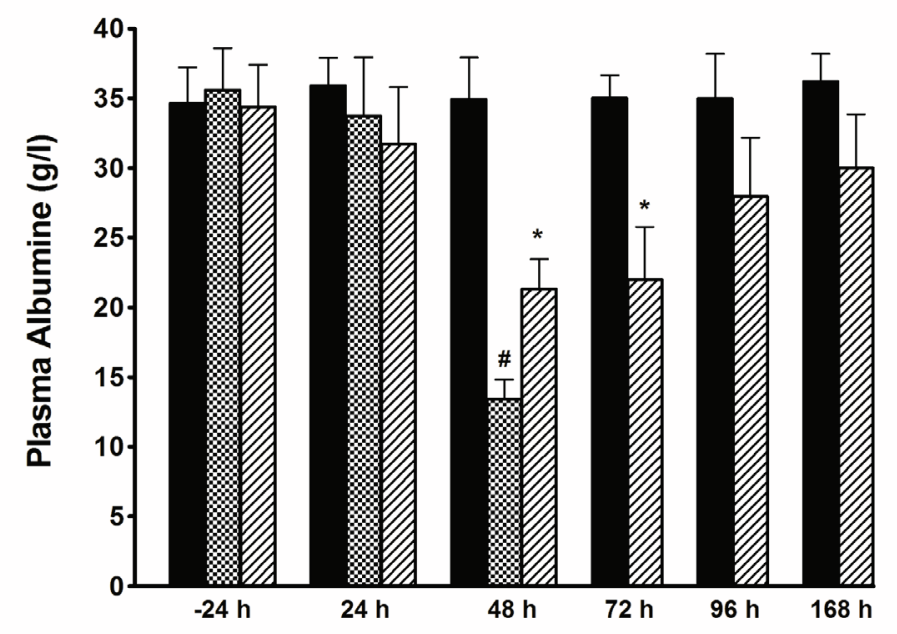

Fig. 3. Changes in plasma bilirubin (A) and albumin (B) levels in healthy Lewis rats exposed to hepatocyte transplantation (Lewis rats + hepatocyte Tx), in Lewis rats with acute liver failure without treatment (untreated Lewis rats with ALF) and in Lewis rats with acute liver failure treated with hepatocyte transplantation (Lewis rats with ALF + hepatocyte Tx). $* P<0.05$ versus the value for Lewis rats + hepatocyte $\mathrm{Tx}$ at the same time point. ${ }^{\#} \mathrm{P}<0.05$ versus all the other values at the same time point.
As shown in Figure 1B, already in the first $24 \mathrm{~h}$ after TAA administration a marked increase in plasma $\mathrm{NH}_{3}$ levels was seen; this was significantly attenuated by hepatocyte Tx. In the animals which survived till the end of experiment (168 h after first TAA injection) $\mathrm{NH}_{3}$ levels were only modestly higher as compared with healthy Lewis rats $(34.2 \pm 2.6$ vs. $24.9 \pm 2.3 \mathrm{mmol} / \mathrm{l}$, $\mathrm{p}<0.05)$.

As shown in Figures $2 \mathrm{~A}$ and $2 \mathrm{~B}$, TAA administration caused significant increases in plasma ALT and AST activities and hepatocyte Tx substantially attenuated these increases: as soon as $96 \mathrm{~h}$ after first TAA administration there were no significant differences in plasma ALT and AST activities as compared with healthy Lewis rats.

As shown in Figure 3A, TAA administration elicited significant elevations in plasma bilirubin level and hepatocyte Tx attenuated this increase, similarly as in the case of ALT and AST activities. Already $72 \mathrm{~h}$ after first TAA administration there were no significant differences in plasma bilirubin levels as compared with healthy Lewis rats. 

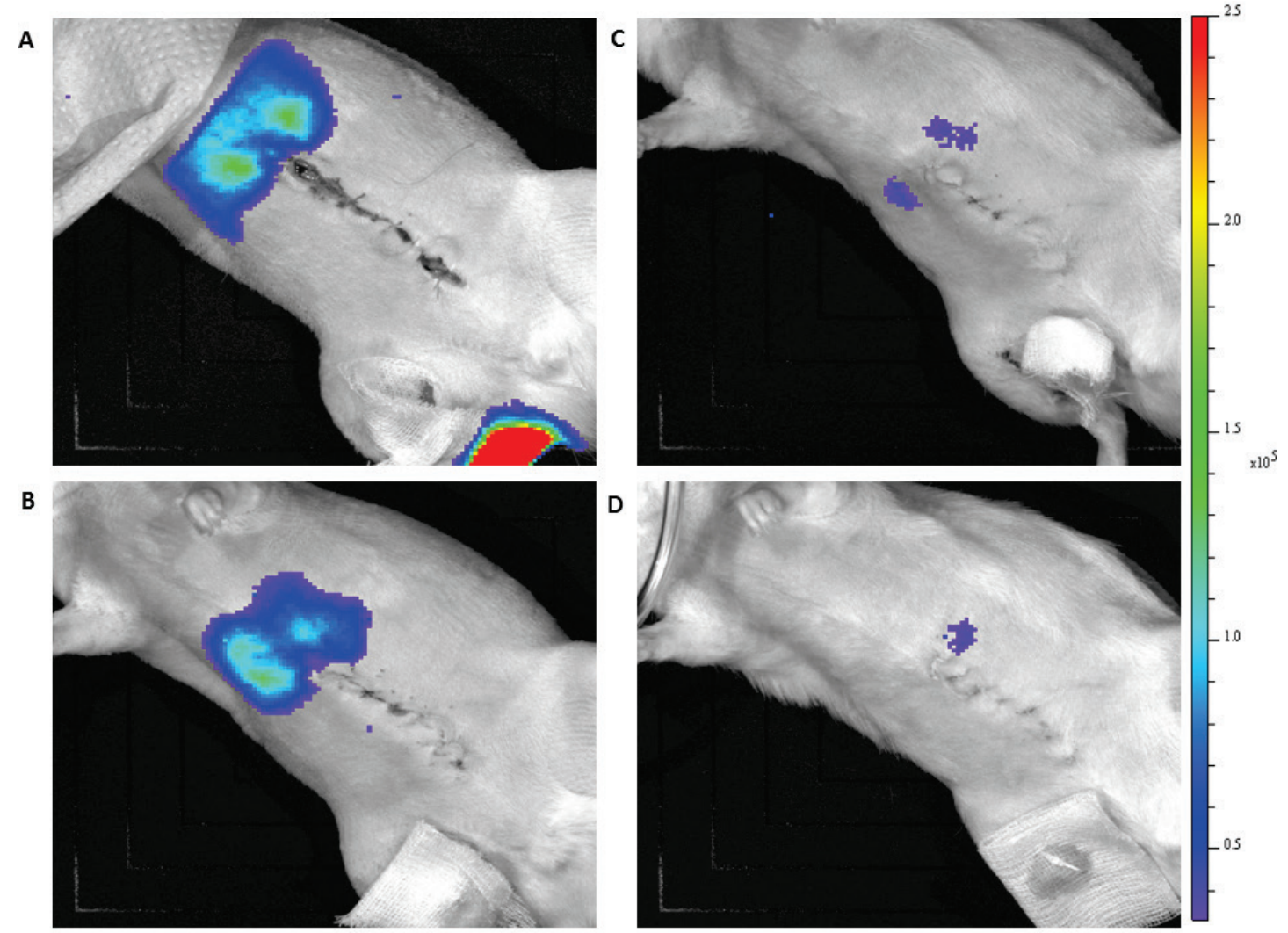

Fig. 4. Representative images from in vivo luciferase bioluminescence analyses in healthy Lewis rats exposed to hepatocyte transplantation at 24 (A), 48 (B), 72 (C) and 168 (D) h post-Tx.
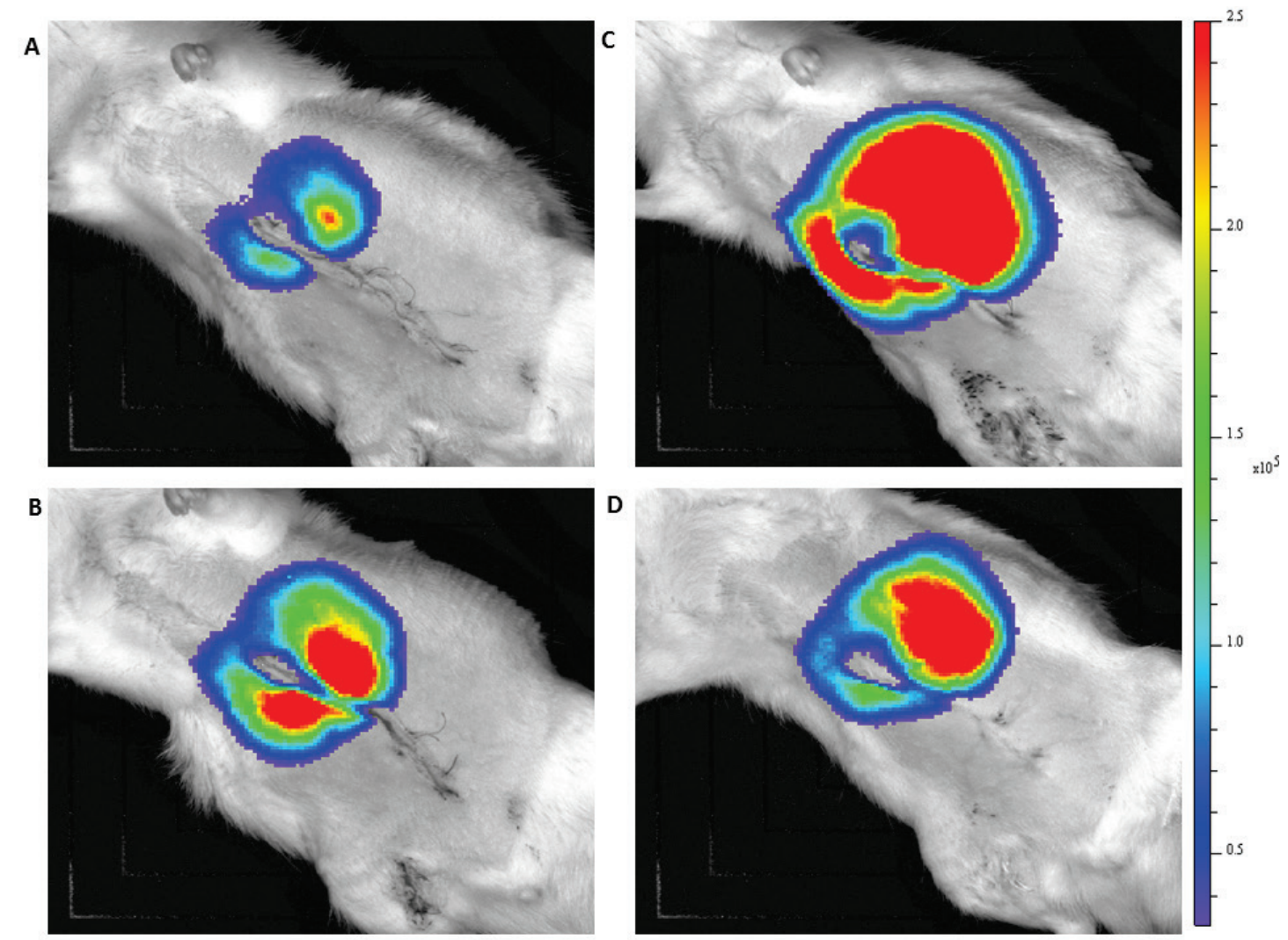

Fig. 5. Representative imagines from in vivo luciferase bioluminescence analyses in Lewis rats with acute liver failure treated with hepatocyte transplantation 24 (A), 48 (B), 72 (C) and 168 (D) $\mathrm{h}$ after hepatocyte transplantation. 
As shown in Figure 3B, TAA administration resulted in a progressive decrease in plasma albumin levels, with the maximal decrease seen $48 \mathrm{~h}$ after first TAA administration $(13.4 \pm 1.4$ vs. $34.9 \pm 2.9 \mathrm{~g} / 1$ in healthy Lewis rats, $p<0.05)$. Hepatocyte $\mathrm{Tx}$ significantly attenuated the decrease in plasma albumin levels and beginning from $96 \mathrm{~h}$ after first TAA administration the plasma albumin levels were not significantly lower as compared with healthy Lewis rats.

Series 2: Hepatocyte viability after $T x$ as assessed in Lewis rats by BLI analysis

As shown in Figure 4, BLI analyses revealed that hepatocytes transplanted into the liver of healthy Lewis rats exhibited only minimal viability from the beginning of the study, and $72 \mathrm{~h}$ after $\mathrm{Tx}$ no sign of viability was seen. In contrast, $24 \mathrm{~h}$ after Tx into the liver of Lewis rats with ALF the viability of transplanted hepatocytes was well visible (Fig. 5A), and was further augmented 48 and $72 \mathrm{~h}$ after Tx (Figs 5B and 5C). It remained appreciable until the end of experiment i.e. $168 \mathrm{~h}$ after hepatocyte Tx (Fig. 5D).

\section{Discussion}

The major finding of the present study is that transplantation of hepatocytes isolated from luc-Lew-Tg markedly attenuated the course of TAA-induced ALF in Lewis rats. This was reflected by improved survival rate and reduced degree of liver injury as indicated by lowering of plasma ALT, $\mathrm{AST}, \mathrm{NH}_{3}$ and bilirubin levels. In this context, it is worthy to underscore the course of plasma bilirubin levels, because even if a major portion of this endogenous organic anion is derived from aging red blood cells, its plasma levels are still accepted as a golden biomarker for the assessment of liver function especially in toxically-induced liver injury (Poynard and Imbert-Bismut 2012). In addition, hepatocyte Tx not only restored the function of detoxification, but also that of biosynthesis: plasma albumin levels in surviving TAA-induced ALF Lewis rats ultimately returned to levels that were not significantly different from those in healthy Lewis rats. Furthermore, BLI analysis of liver tissue clearly demonstrated that in TAA-damaged livers transplanted hepatocytes were fully viable throughout the experiment. Taken together, our present findings strongly indicate that hepatocyte Tx into the liver via portocaval application can attenuate the course of TAA-induced ALF in Lewis rats.
The value of these findings is enhanced by the experimental design which mimics the clinical situation: hepatocyte Tx was initiated after the signs of ALF became apparent. This is of special importance because in some previous studies the transplantation was performed before induction of ALF, then the translation of the results into clinical practice is doubtful (Amano et al. 2011, Hughes et al. 2012, Sgroi et al. 2009, Struecker et al. 2014). Second, the animal experimental model applied should resemble the clinical condition as closely as possible (Butterworth et al. 2009, Ternblache and Hickman 1991, Tunon et al. 2009). We have recently provided evidence (Koblihová et al. 2014) that TAAinduced ALF is the optimal model which fulfills most of the required criteria (Butterworth et al. 2009, Rahman and Hodgson 2000).

In this regard, it should be emphasized that attempts to create artificial and bioartificial systems supporting regeneration of the patient's liver ("bridging" to regeneration or to a time point when a suitable liver for OLT becomes available) have not brought satisfactory results (Struecker et al. 2014, Stutchfield et al. 2011). Some meta-analyses (Kjaergard et al. 2003, Struecker et al. 2014) have reported no beneficial effects of application of artificial and bioartificial liver support systems on the mortality of patients with ALF. It was shown that while such support devices are safe for acute application and can improve biochemical markers (Prazak et al. 2013, Ryska et al. 2009, Ryska et al. 2012, Struecker et al. 2014, Stutchfield et al. 2011), they do not generally improve survival rate of patients with ALF (Pless 2010, Struecker et al. 2014, Stutchfield et al. 2011) and, remarkably, no bioartificial liver support system has obtained approval from U.S. Food and Drug Administration for standard clinical uses (Arenas-Herrera et al. 2013). It will be noted that the original notion that the critical "failed" function in ALF is detoxification, and thus approaches ensuring this are adequate for treatment of ALF, proved inaccurate (Banares et al. 2013, Selden and Hodgson 2004). The commonly used systems cannot fully replace the diversity and complexity of liver function: detoxification is more complex than simple removal of albumin-bound toxins, and regulation of homeostasis means more than normalization of plasma electrolyte, glucose and hydrogen ions levels (Suchy 2009). Therefore, alternative strategies for treatment of ALF that would address the complexity of disturbed physiological functions of the liver are heavily investigated. In the light of recent research hepatocyte Tx 
which restores missing liver functions in a natural way seems to be a very promising therapeutical approach (Pless 2010).

So far, hepatocyte Tx has been performed for treatment of inborn metabolic liver diseases which are caused by a deficiency of a single hepatic enzyme or protein (e.g. Crigler-Najjar syndrome type I, urea cycle defects and Wilson's disease) and can be corrected with engraftment of hepatocytes expressing the gene involved. Such applications were relatively successful, at least as a method of "bridging to transplantation" (Dhawan et al. 2010, Filippi and Dhawan 2014, Yu et al. 2012, Waelzlein et al. 2009). In contrast, clinical studies of hepatocyte Tx in ALF yielded poor results, and it was proposed that the number of transplanted hepatocytes might be sufficient to correct single inborn metabolic errors but not to provide full compensation of liver function (Struecker et al. 2014). However, our present data show that hepatocyte Tx into the liver in the amount of $5 \%$ of parenchymal cell mass is sufficient to attenuate the course of TAA-induced ALF in Lewis rats. In this regard, it is important to emphasize that the amount of transplanted hepatocytes in the present study was increased in accordance with recent findings of studies employing the hepatocyte $\mathrm{Tx}$ for the treatment of liverbased metabolic diseases to the quantity $2 \times 10^{6}$ (for review see Filippi and Dhawan 2014). The exact justification for the amount of used hepatocytes in our present study is given in the Methods section. Our current findings indicate that hepatocyte $\mathrm{Tx}$ could serve as a therapeutical method either as a "bridge to transplantation" or even as a "bridge to regeneration".

The second major finding of the present study is that BLI analyses revealed that hepatocytes transplanted into the liver of Lewis rats with TAA-induced ALF (but not into the liver of healthy Lewis rats) exhibited distinct viability until the end of the experiment. The finding demonstrates also that our current approach and technique to transplant hepatocytes directly into the TAA-damaged liver is feasible and safe. This is very important because direct delivery into the liver has been earlier questioned for safety reasons, and alternative sites, such as the spleen and peritoneal cavity have been suggested (Struecker et al. 2014, Waelzlein et al. 2009). However, even though hepatocyte Tx into these other sites have been shown to be safe and to some extent effective, a major limitation of this approach is that it does not support regeneration of damaged liver tissue (Struecker et al. 2014, Wertheim et al. 2012, Waelzlein et al. 2009). Of particular interest is also our finding that hepatocytes transplanted into the liver of healthy Lewis rats exhibited minimal viability immediately after $\mathrm{Tx}$, and $72 \mathrm{~h}$ later no sign of viability was seen. These findings resemble the situation in another newly examined liver support strategy, the technique of recellularization of decellularized liver. The studies showed that in order to keep the masses of hepatocytes metabolically active outside their original environment, it is necessary to remove first all cells and other antigenic material from the liver (e.g. porcine) and obtain a non-immunogenic extracellular matrix (decellularization step). Only then can the matrix be repopulated with cells and after their maturation the neo-liver can be used as a bioreactor (recellularization concept) (Arenas-Herrera et al. 2013, Struecker et al. 2014, Yagi et al. 2013). Taken together, our present and the above-quoted findings suggest that for successful preservation of viability of transplanted hepatocytes, the natural cells and other antigenic material from the recipient liver should first be destroyed. We are aware that our present study was not designed to evaluate such a proposal and interpretation of our BLI data remains hypothetical. Future studies are required to address the mechanism(s) responsible for the different course of viability of transplanted hepatocytes in healthy Lewis rats compared to Lewis rats with ALF. However, it is important to emphasize that BLI analyses was performed in a separate groups of from those where the effects of hepatocyte on the course of TAA-induced ALF was examined. The reason for the separate series of experiments is that BLI analyses requires repetitive anesthesia with $2 \%$ isoflurane and this procedure could negatively alter the major followed end-point of the present study (i.e. effects of hepatocyte Tx on the survival rate in TAA-induced ALF). Moreover, it is important to recognize that despite marked attenuation the course of TAA-induced ALF by hepatocyte Tx the final survival rate was still only $15 \%$. The limitation of our present study is that we cannot provide a sufficient explanation for this fact, because e.g. we do not have data about the viability of transplanted hepatocyte in animals that died during the first $72 \mathrm{~h}$ of our experiment. It is obvious that future studies are needed to address this issue.

In this context, it is worthwhile to briefly discuss, why in our studies TAA-induced ALF model is used. The major reason is that we have in our recent study unequivocally proven (Koblihova et al. 2014) that this model meets criteria that were originally suggested for an ideal animal model of ALF (if TAA is 
administrated in accordance with our design) (Terblanche and Hickman 1991) and are as follow: a) reversibility, i.e. that induced liver failure should be potentially reversible; b) reproducibility, i.e. that degree of liver damage should be standardized, especially within the major endpoint which is the death of the animal; c) death cause, i.e. that death should be a direct result of the insult to the liver; d) therapeutic window, i.e. that sufficient time should available between the insult and the death; e) minimum hazard to personnel, i.e. that the toxin should present minimal risk to investigators. We are aware that our current findings are limited only to the course of TAA-induced ALF, however recently hepatocyte Tx was successfully used in the treatment of another chemical models of ALF (e.g. D-galactosamine-induced ALF) (Puppi et al. 2014) and therefore we believe that our present results should be reproducible in other models of ALF and such studies are necessary to be performed in future.

In conclusion, the results of the present study show that hepatocyte $\mathrm{Tx}$ into the liver can attenuate the course of TAA-induced ALF in Lewis rats. This information should be considered in attempts to develop new therapeutic approaches or tools for treatment of ALF.

\section{Conflict of Interest}

There is no conflict of interest.

\section{Acknowledgements}

This study was supported by Ministry of Health of the Czech Republic within the project for the development of research organization 00023001 (IKEM) and MO 2012 (CMH) - institutional support. The Center for Experimental Medicine (IKEM) received financial support from the European Commission within the Operational Program Prague-Competitiveness; project "CEVKOON" (\#CZ.2.16/3.1.00/22126). Within project "CEVKOON" the Living Image software was developed with cooperation with Aura Medical Ltd. for BLI analyses of transplanted hepatocytes.

\section{References}

AMANO H, HINO H, TATENO C, EMOTO K, IMAOKA Y, YAMASAKI C, ITAMOTO T, TASHIRO H, ASAHARA T, OHDAN H, YOSHIZATO K: Therapeutic potential of propagated hepatocyte transplantation in liver failure. J Surg Res 167: e29-e37, 2011.

ARENAS-HERRERA JE, KO IK, ATALA A, YOO JJ: Decellularization for whole organ bioengineering. Biomed Mater 8: 014106, 2013.

BAÑARES R, CATALINA MV, VAQUERO J: Liver support systems: Will they ever reach prime time? Curr Gastroenterol Rep 15: 312, 2013.

BERG CL, MERION RM, SHEARON TH, OLTHOFF KM, BROWN Jr RS, BAKER TB, EVERSON GT, HONG JC, TERRAULT N, HAYASHI PH, FISHER RA, EVERHART JE: Liver transplant recipient survival benefit with living donation in the model for endstage liver disease allocation era. Hepatology 54: 1313-1321, 2011.

BERNAL W, WENDON J: Acute liver failure. N Engl J Med 369: 2525-2534, 2013.

BERRY MN, BARRITT GJ, EDWARDS AM: High-yield preparation of isolated hepatocytes from rat liver. In: Isolated Hepatocytes. Preparation, Properties and Applications. BURDON RH, VAN KNIPPENBERG PH (eds), Elsevier, New York, 1991, pp 15-58.

BOOTH C, SOKER T, BAPTISTA P, ROSS CL, SOKER S, FAROOQ U, STRATTA RJ, ORLANDO G: Liver bioengineering: current status and future perspectives. World J Gastroenterol 18: 6926-6934, 2012.

BUTTERWORTH RF, NORENBERG MD, FELIPO V, FERENCI P, ALBRECHT J, BLEI AT; MEMBERS OF THE ISHEN COMMISSION ON EXPERIMENTAL MODELS OF HE: Experimental models of hepatic encephalopathy: ISHEN guidelines. Liver Int 29: 783-788, 2009.

DHAWAN A, PUPPI J, HUGHES RD, MITRY RR: Human hepatocyte transplantation: current experience and future challenges. Nat Rev Gastroenterol Hepatol 7: 288-298, 2010.

EGUCHI S, LILJA H, HEWITT WR, MIDDLETON Y, DEMETRIOU AA, ROZGA J: Loss and recovery of liver regeneration in rats with fulminant hepatic failure. J Surg Res 72: 112-122, 1997.

FILIPPI C, DHAWAN A: Current status of human hepatocyte transplantation and its potential for Wilson's disease. Ann N Y Acad Sci 1315: 50-55, 2014. 
FUKUMITSU K, YAGI H, SOTO-GUTIERREZ A: Bioengineering in organ transplantation: targeting the liver. Transplant Proc 43: 2137-2138, 2011.

GARNOL T, ENDLICHER R, KUČERA O, DRAHOTA Z, ČERVINKOVÁ Z: Impairment of mitochondrial function of rat hepatocytes by high fat and oxidative stress. Phys Res 63: 271-274, 2014.

GERMANI G, THEOCHARIDOU E, ADAM R, KARAM V, WENDON J, O'GRADY J, BURRA P, SENZOLO M, MIRZA D, CASTAING D, KLEMPNAUER J, POLLARD S, PAUL A, BELGHITI J, TSOCHATIZIS E, BURROUGHS AK: Liver transplantation for acute liver failure in Europe: outcomes over 20 years from the ELTR database. $J$ Hepatol 57: 288-296, 2012.

HAKAMATA Y, MURAKAMI T, KOBAYASHI E: "Firefly rats" as an organ/cellular source for long-term in vivo bioluminescent imaging. Transplantation 81: 1179-1184, 2006.

HUGHES RD, MITRY RR, DHAWAN A: Current status of hepatocyte transplantation. Transplantation 93: 342-347, 2012.

JITRARUCH S, DHAWAN A, HUGHES RD, FILIPPI C, SOONG D, PHILIPPEOS C, LEHEC SC, HEATON ND, LONGHI MS, MITRY RR: Alginate microencapsulated hepatocytes optimized for transplantation in acute liver failure. PloS One 9: e113609, 2014.

KASAHARA N, KIKUCHI T, DOI J, TERATANI T, FUJIMOTO Y, UEMOTO S, YASUDA Y, KOBAYASHI E: Luminescence-based assay to screen preservation solutions for optimal ability to maintain viability of rat intestinal grafts. Transplant Proc 45: 2486-2490, 2013.

KAWAHARA T, TOSO C, DOUGLAS DN, NOURBAKHSH M, LEWIS JT, TYRRELL DL, LUND GA, CHURCHILL TA, KNETEMAN NM: Factors affecting hepatocyte isolation, engraftment, and replication in an in vivo model. Liver Transpl 16: 974-982, 2010.

KJAERGARD LL, LIU J, ALS-NIELSEN B, GLUUD C: Artificial and bioartificial support systems for acute and acute-on-chronic liver failure. JAMA 289: 217-222, 2003.

KOBLIHOVA E, MRÁZOVÁ I, VERNEROVÁ Z, RYSKA M: Acute liver failure induced by thioacetamide: selection of optimal dosage in Wistar and Lewis rats. Physiol Res 63: 491-503, 2014.

LEE WM: Acute liver failure. Semin Respir Crit Care Med 33: 36-45, 2012.

LEE WM, STRAVITZ RT, LARSON AM: Introduction to the revised American association for the study of liver diseases position paper on acute liver failure 2011. Hepatology 55: 965-967, 2012.

LOUKOPOULOS I, SFINIADAKIS I, PILLAI A, KONSTANTOULAKIS M, ANDROULAKIS G, BONATSOS V, ZOGRAFOS G, PAPALOIS A: Mycophenolate mofetil and sirolimus in hepatocyte transplantation in an experimental model of toxic acute liver failure. J Invest Surg 27: 205-213, 2014.

MAEDA M, KASAHARA N, DOI J, IIJIMA Y, KIKUCHI T, TERATANI T, KOBAYASHI E: A luminance-based heart chip assay for assessing the efficacy of graft preservation solutions in heart transplantation in rats. Heart Asia 17: 7-14, 2013.

MAO SA, GLORIOSO JM, NYBERG SL: Liver regeneration. Transl Res 163: 352-362, 2014.

PAREJA E, CORTÉS M, GÓMEZ-LECHÓN MJ, MAUPOEY J, SAN JUAN F, LÓPEZ R, MIR J: Current status and future perspectives of hepatocyte transplantation. Cir Esp 92: 74-81, 2014.

PLESS G: Bioartificial liver support systems. Methods Mol Biol 640: 511-523, 2010.

POYNARD T, IMBERT-BISMUT F: Laboratory testing for liver disease. In: Zakim and Boyer's Hepatology A Textbook of Liver Disease. BOYER TD, MANNS MP, SANYAL AJ (eds), Elsevier Saunders, Philadelphia, 2012, pp 201-215.

PRAZAK J, LASZIKOVA E, PANTOFLICEK T, RYSKA O, KOBLIHOVA E, RYSKA M: Cerebral microdialysis reflects the neuroprotective effect of fractionated plasma separation and adsorption in acute liver failure better and earlier than intracranial pressure: a controlled study in pigs. BMC Gastroenterol 13: 98, 2013.

PUPPI J, MODO M, DHAWAN A, LEHEC SC, MITRY RR, HUGHES RD: Ex vivo magnetic resonance imaging of transplanted hepatocytes in a rat model of acute liver failure. Cell Transplant 23: 329-343, 2014.

RAHMAN TM, HODGSON HJF: Animal models of acute hepatic failure. Int J Exp Pathol 81: 145-157, 2000.

RYSKA M, LASZIKOVA E, PANTOFLICEK T, RYSKA O, PRAZAK J, KOBLIHOVA E: Fractionated plasma separation and adsorption significantly decreases intracranial pressure in acute liver failure: experimental study. Eur Surg Res 42: 230-235, 2009. 
RYSKA O, PANTOFLICEK T, LASZIKOVA E, PRAZAK J, KOBLIHOVA E, RYSKA M: Artificial liver support system reduces intracranial pressure more effectively than bioartificial system: an experimental study. Int $J$ Artif Organs 35: 503-510, 2012.

SALIBA F, SAUMEL D: Acute liver failure: current trends. J Hepatol 59: 6-8, 2013.

SEGLEN PO: Preparation of isolated rat liver cells. Methods Cell Biol 13: 29-83, 1976.

SELDEN C, HODGSON H: Cellular therapies for liver replacement. Transpl Immunol 12: 273-288, 2004.

SGROI A, SERRE-BEINIER V, MOREL P, BUHLER L: What clinical alternatives to whole liver transplantation? Current status of artificial devices and hepatocyte transplantation. Transplantation 87: 457-466, 2009.

STRUECKER B, RASCHZOK N, SAUER IM: Liver support strategies: cutting-edge technologies. Nat Rev Gastroenterol Hepatol 11: 166-176, 2014.

STUTCHFIELD BM, SIMPSON K, WIGMORE SJ: Systematic review and meta-analysis of survival following extracorporeal liver support. Br J Surg 98: 623-631, 2011.

SUCHY FJ: Hepatobiliary function. In: Medical Physiology: A Cellular and Molecular Approach. BORON WF, BOULPAEP EL (eds), Saunders Elsevier, Philadelphia, 2009, pp 980-1008.

TERBLANCHE J, HICKMAN R: Animals models of fulminant hepatic failure. Dig Dis Sci 36: 770-774, 1991.

TRITTO G, DAVIES NA, JALAN R: Liver replacement therapy. Semin Respir Crit Care Med 33: 70-79, 2012.

TUÑÓN MJ, ALVAREZ M, CULEBRAS JM, GONZÁLES-GALLEGO J: An overview of animal models for investigating the pathogenesis and therapeutic strategies in acute hepatic failure. World J Gastroenterol 15: 3086-3098, 2009.

WAELZLEIN JH, PUPPI J, DHAWAN A: Hepatocyte transplantation for correction of inborn errors of metabolism. Curr Opin Nephrol Hypertens 18: 481-488, 2009.

WERTHEIM JA, BAPTISTA PM, SOTO-GUTIERREZ A: Cellular therapy and bioartificial approaches to liver replacement. Curr Opin Organ Transplant 17: 235-240, 2012.

WLODZIMIROW KA, ESLAMI S, CHAMULEAU RA, NIEUWOUDT M, ABU-HANNA A: Prediction of poor outcome in patients with acute liver failure - systematic review of prediction models. PLoS One 7: e50952, 2012.

WU Z, HAN M, CHEN T, YAN W, NING Q: Acute liver failure: mechanisms of immune-mediated liver injury. Liver Int 30: 782-794, 2010.

YAGI H, FUKUMITSU K, FUKUDA K, KITAGO M, SHINODA M, OBARA H, ITANO O, KAWACHI S, TANABE M, COUDRIET GM, PIGANELLI JD, GILBERT TW, SOTO-GUTIERREZ A, KITAGAWA Y: Human-scale whole-organ bioengineering for liver transplantation: a regenerative medicine approach. Cell Transplant 22: 231-242, 2013.

YAMASHIKI N, SUGAWARA Y, TAMURA S, NAKAYAMA N, OKETANI M, UMESHITA K, UEMOTO S, MOCHIDA S, TSUBOUCHI H, KOKUDO N: Outcomes after living donor liver transplantation for acute liver failure in Japan: results of a nationwide survey. Liver Transpl 18: 1069-1077, 2012.

YU Y, FISHER JE, LILLEGARD JB, RODYSILL B, AMIOT B, NYBERG SL: Cell therapies for liver diseases. Liver Transpl 18: 9-21, 2012.

ZHAO P, WANG C, LIU W, CHEN G, LIU X, WANG X, WANG B, YU L, SUN Y, LIANG X, YANG H, ZHANG F: Causes and outcomes of acute liver failure in China. PLoS One 8: e80991, 2013. 